\title{
OPERAÇÕES BACK TO BACK COMO FORTALECIMENTO DE MARCA
}

\author{
OPERATIONS BACK TO BACK AS BRAND FORTIFICATION
}

Guilherme Teston ${ }^{1}$, Thiago Henrique Almino Francisco ${ }^{2}$, Yuri Borba Vefago ${ }^{3}$

\begin{abstract}
RESUMO
Back to Back são operações triangulares, onde uma empresa intermediária compra produtos em um país no exterior e vende estes produtos para outro país também no exterior. Essa operação é sustentada pela marca da empresa que diferencia seus produtos dos concorrentes. Diante disso, o presente estudo teve como objetivo analisar como uma marca pode influenciar na compra de mercadorias dessas operações. O trabalho se caracterizou como uma pesquisa exploratória e descritiva quanto aos fins de investigação. A população alvo foi delimitada numa empresa cerâmica da região sul catarinense. As entrevistas foram realizadas com sujeitos com experiência sobre o tema proposto. Por transmitirem confiança e segurança, verificou-se que as marcas influenciam os clientes a utilizarem essa operação. O Back to Back atua como um fortalecedor de marca, pois posiciona a empresa como completa frente ao mercado devido à variedade de produtos que podem ser oferecidos para os consumidores.
\end{abstract}

Palavras-chave: Operação; Back to Back; Marca.

\begin{abstract}
Back to Back are triangular operations, where an intermediary company buys products in a foreign country and sells these products to another country abroad. This operation is supported by the company's brand that differentiates its products from competitors. Therefore, this study aimed to analyze how a brand can influence the purchase of goods such transactions. The work was characterized as an exploratory and descriptive research about the research purposes. The target population was defined in a ceramics company. Interviews were conducted with individuals with experience on the theme. By transmitting reliability and safety, it was found that the marks influence customers to use this operation. The Back to Back acts as a strengthening mark, for positioning the company as a complete before the market due to the variety of products that can be offered to consumers.
\end{abstract}

Keywrds: Operations; Back to Back; Brand.

\footnotetext{
${ }^{1}$ Acadêmico e pesquisador na UNESC.

${ }^{2}$ Professor e pesquisador na UNESC.

${ }^{3}$ Acadêmico e pesquisador na UNESC.
} 


\section{INTRODUÇÃO}

A operação Back to Back consiste em uma empresa intermediária localizada em um determinado país, comprando um produto de uma empresa estrangeira e revendendo esta mercadoria para uma terceira empresa também no exterior, sem que a mercadoria circule fisicamente pelo seu território.

As empresas utilizam essa operação para suprir uma demanda de mercado que elas não conseguem atender seja por não produzirem, seja por não ter interesse em produzir ou seja por não conseguir suprir essa demanda com a produção própria.

No entanto, os produtos oferecidos pela empresa nessa operação devem ter qualidade igual ou superior aos produtos da organização, pois os clientes esperam receber um produto com, no mínimo, os mesmos atributos da produção própria. Desse modo, a marca da empresa é utilizada nessa operação.

Ante o exposto, é importante que as empresas parceiras no outro país sejam confiáveis e profissionais que tenham produtos e serviços de qualidade semelhante à empresa intermediária. Possuir conhecimento profundo sobre comércio exterior também é essencial para que saber identificar qual a melhor forma de conduzir a operação.

Diante deste contexto, a pesquisa em questão tem como objetivo analisar como as operações podem influenciar no fortalecimento da marca de uma empresa.

\section{A ORGANIZAÇÃO BASEADA NO CONHECIMENTO}

A Era do Conhecimento implementou mudanças dentro e fora das organizações (MACIEL; ALBAGLI, 2007). De acordo com Carvalho (2000), a mudança de uma sociedade industrial para uma sociedade do conhecimento trouxe novas formas de gestão nas organizações. Ao invés de focar em capital e trabalho padronizado para se obter sucesso organizacional, as empresas passaram a investir em pessoas e nas informações para criar e obter conhecimento para si.

As transformações e inovações tecnológicas que estão ocorrendo atualmente no mundo fizeram com que as organizações mudassem o jeito com que elas gerem seus negócios e a forma como olham para o mercado. As empresas baseadas em conhecimento visam a criação e aplicação do conhecimento através de elementos que compõe o conhecimento organizacional (JOÃO; FISCHMANN; MAGALHÃES, 2005; ROSSETI, 2008). 
As organizações com enfoque em conhecimento o utilizam como forma de diferenciação e vantagem competitiva, sendo as pessoas os principais ativos dessa diferenciação. Segundo Santos (2005), conhecimento é a experiência, valores e criatividade que as pessoas possuem ou adquiriram. Sendo assim, esse conhecimento é utilizado para resolver problemas, tomar decisões, definir estratégias, melhorar processos e tarefas, desenvolver novos produtos e serviços nas organizações.

$\mathrm{Na}$ economia do conhecimento, o principal insumo para produzir, fazer, comprar e vender é o conhecimento. Portanto, essa economia possui o conhecimento e os relacionamentos como as principais fontes de riqueza para uma organização. Nessa economia, as fontes de riqueza são os ativos intangíveis que geram produtos ou serviços através do conhecimento. Por esse motivo, é importante saber administrar e gerenciar a capacidade de gerar, armazenar, recuperar, processar e transmitir estes conhecimentos nas empresas (SANTOS, 2005; TIGRE, 2005).

Diante desses elementos, é importante que os trabalhadores possuam diversas competências que faça com que ele se adapte às diferentes exigências de cada mercado (SCHAPIRO, 2009). As pessoas que atuam nessa economia devem encontrar a informação mais confiável, interpretá-las e produzirem conhecimento que quando usado gera valor para as organizações. Dessa forma, pode-se entender que as pessoas são o capital ou ativo mais importante da economia baseada no conhecimento (DZIEKANIAK; ROVER, 2011).

Em uma organização baseada no conhecimento, o desenvolvimento dos ativos intangíveis é um dos maiores objetivos de sua gestão (SANTOS, 2005). A origem desses ativos está no capital intelectual, nas práticas organizacionais e nas atividades relacionadas com as inovações (RITTA, 2010). Esses ativos tem a característica de não se desgastarem com o uso, pelo contrário, quanto mais for compartilhado maior valor será agregado (SANTOS, 2005). Entretanto, a principal e mais importante característica dos ativos intangíveis é sua exclusividade em cada organização. Eles devem ser valiosos, raros, inimitáveis e insubstituíveis, assim as empresas criam vantagem competitiva sustentável em relação às outras organizações no mercado (BATTELLI, 2011).

\section{A MARCA COMO UM ATIVO INTANGÍVEL}

Como uma proposição de ativo intangível, a marca é o maior ativo das empresas na sociedade do conhecimento. Na década de 90, a Microsoft ultrapassou a General Electric 
(GE), até então maior empresa no mundo, em termos de valor de mercado. A relevância desse acontecimento se dá, porque foi a primeira vez que uma organização baseada em conhecimento ultrapassou uma empresa de máquinas e equipamentos, baseada nas características industriais (NUNES; HAIGH, 2003). Essas organizações utilizam o conhecimento em prol de suas marcas e, assim, conseguem agregar valor a seus produtos e serviços.

Em seu resgate histórico, as marcas começaram a ser usadas na Idade Média e serviam para diferenciar e proteger os produtos dos fabricantes (que antes eram vendidos sem identificação alguma), e para os consumidores a marca os ajudava a identificar produtos de baixa qualidade (KOTLER, 1995). Com o passar do tempo, a marca já não servia mais só para identificar e proteger os produtos, mas passou a agregar valor ao mesmo através de estratégias diversas.

Kotler (1995) definiu marca como: "um nome, termo, sinal, símbolo, ou design, ou ainda uma combinação deles, visando à identificação de produtos ou serviços de uma empresa ou grupo de empresas, bem como sua diferenciação dos concorrentes".

Para construir marcas é imprescindível conhecer o cliente potencial e a concorrência, além de estabelecer comunicação com o público de interesse e investir nas diferentes formas de comunicação para com esse público (KHAUAJA, 2008).

Existem quatro aspectos importantes para construir a marca: imagem, identidade, reputação e o posicionamento da empresa. No aspecto da imagem, a personalidade da marca é importante. A forma como a empresa se relaciona com seu público e com o meio ambiente impactam na construção de uma marca forte, ou seja, como a marca é percebida. A identidade da marca visa identificar as características da marca e representar a marca como ela gostaria que fosse percebida pelo consumidor. A reputação é a reação emocional ou afetiva, boa ou ruim, que o público interno ou externo tem da marca. Por fim, o posicionamento da marca representa como uma organização se propõe a entregar um produto ou serviço de forma diferenciada das outras organizações, assim justificando a escolha do cliente por aquela marca (TAVARES, 1998; AAKER; JOACHIMSTHALER, 2000).

As empresas ainda devem considerar três aspectos psicológicos para construir uma marca: cognitivo, afetivo e conativo. O componente cognitivo são o conhecimento e as crenças do cliente sobre um produto ou serviço. $\mathrm{O}$ afetivo representa o sentimento que o 
consumidor tem sobre um produto ou serviço. E o conativo representa as tendências de comportamento sobre um produto ou serviço (TAVARES, 1998).

A construção da marca é um fator crucial de sucesso para as organizações, pois nos dias atuais a concorrência acirrada e as constantes exigências dos clientes tornam a marca um diferencial no mercado. Por esse motivo, é importante que se desenvolva uma estratégia de marca que crie diferenciação em relação aos concorrentes e que justifique a decisão de compra de um consumidor (MAGALHÃES, 2006).

As marcas são capazes de criar vantagens competitivas únicas e muito difíceis de imitar, devido aos atributos que uma marca possui e que fazem com que o consumidor escolha um produto ou serviço de uma determinada marca ao invés da concorrente (TAVARES, 1998).

Os atributos de marca devem ter o objetivo de proporcionar benefícios para os consumidores e estes devem relacionar-se com os valores pessoais dos clientes. Esses benefícios são divididos em três categorias: benefícios funcionais, experienciais e simbólicos.

Os benefícios funcionais proporcionam utilidade funcional para o consumidor, porém, geralmente, não diferenciam o produto e são facilmente imitadas. Eles estão ligados às necessidades fisiológicas, de segurança e de aceitação. Os Benefícios experienciais estão relacionados às sensações positivas experimentadas durante o uso de um produto ou serviço. Por último, os benefícios simbólicos estão relacionados aos atributos extrínsecos ou nãorelacionados ao produto, onde a aprovação social e autoestima se tornam a base para atrair os consumidores (TAVARES, 1998).

O conhecimento da marca, segundo Aaker (1998), é a capacidade que um comprador tem de reconhecer ou se recordar de uma marca como integrante de uma categoria de produtos.

Tavares (1998), afirma que a identidade da marca deve contribuir para a compreensão dos valores e propósitos básicos da empresa. Khauaja (2008) afirma que a identidade da marca é um conjunto de associações que o estrategista de marca procura criar ou manter. A partir dessas definições entende-se que identidade de marca é a concepção que ela tem de si, ou seja, é como a empresa gostaria que sua marca fosse percebida pelos consumidores (AAKER; JOACHIMSTALER, 2000).

Diferentemente da identidade, a imagem da marca representa a maneira como a marca é vista pelos consumidores, sendo que a imagem é formada pela identidade da marca e por 
seus valores. Khauaja (2008) corrobora esta assertiva definindo a imagem como a decodificação feita pelo público de todos os sinais emitidos pela marca. Diante disso, a imagem da marca é definida como o conjunto de crenças, atitudes e impressões que os consumidores têm em relação a marca, sendo que esta percepção pode ser positiva, negativa ou neutra. A imagem da marca cria características exclusivas, distinguindo-as de outras marcas e tornando praticamente impossível copiá-las (TAVARES, 1998).

O conhecimento da marca se dá através da construção da identidade e imagem da marca que estão ligados a qualidade percebida pelos compradores (DIAS, 2004), e ela é definida como a percepção que o consumidor tem da qualidade ou superioridade de um produto ou serviço em relação aos concorrentes. Além disso, a qualidade é intangível e está diretamente ligada às associações que o consumidor faz com relação aos atributos da marca (AAKER, 1998).

De acordo com Aaker (1998), a associação de marca está ligada à uma imagem na memória das pessoas. Essa associação é criada através do posicionamento da marca. Posicionamento da marca pode ser definido como o posicionamento de uma marca na cabeça do consumidor que é baseada nos valores que a marca possui e que a diferencia das outras $\mathrm{O}$ posicionamento da marca envolve uma rede associativa baseada na memória de valor que os consumidores têm da marca e que atuam como um fator decisivo de compra (MARSDEN, 2002; TAVARES, 1998).

\section{BRANDING}

As marcas necessitam de um bom gerenciamento para que tenham sucesso no atual mercado competitivo. Esse processo de gerenciamento de marcas é conhecido como Branding. Martins (2006, p. 8) define Branding como:

Branding é o conjunto de ações ligadas à administração das marcas. São ações que, tomadas com conhecimento e competência, levam as marcas além de sua natureza econômica, passando a fazer parte da cultura, e influenciar a vida das pessoas.

Já para Lindstrom (2007), “Branding sempre foi a criação de laços emocionais entre a marca e o consumidor. Como em qualquer relacionamento, as emoções se baseiam na informação captada por nossos sentidos".

O objetivo de a marca utilizar os sentidos humanos é criar uma memória sensorial para que os consumidores se lembrem dessa marca através de algum momento sensitivo e despertados por alguma associação feita através de propagandas na televisão, por exemplo. 
Segundo Brito e Zuza (2009), a memória sensorial pode ser criada através da associação de um determinado estímulo com a marca, como por exemplo, o cheiro de uma comida, o perfume de um produto, o som de uma garrafa sendo aberta, etc.

Llamas (2013) afirma que o Branding é um processo que gera uma experiência de acumulação e produza uma imagem mental traduzida em reconhecimento e atributos de associações ante ao seu público alvo. Isto é, o Branding gerencia o conhecimento, as associações e a qualidade percebida das marcas para atrair clientes, fideliza-los e agregar valor de mercado para si (BRITO; ZUZA, 2009).

\section{AS OPERAÇÕES DE BACK-TO-BACK}

Para o Banco do Brasil (2015), as operações Back to Back são operações triangulares, ou seja, são realizadas por três empresas distintas, caracterizadas por uma empresa brasileira comprando mercadoria de uma empresa situada em outro país e revendendo esta mercadoria para uma terceira empresa também situada no exterior. Toda a operação de compra e revenda ocorre no exterior, sem que esta circule fisicamente pelo território da empresa brasileira.

No âmbito cambial, não há necessidade de liberação do mesmo para a realização dessa operação, porém os processos de recebimento e pagamento destes recursos devem ser feitos diretamente com instituições autorizadas pelo Banco Central (BANCO CENTRAL DO BRASIL, 2015).

O Back to Back ainda possui variações com que se pode trabalhar, como por exemplo, a empresa brasileira exporta um produto para uma empresa no exterior que agrega um complemento e a partir disso realiza a exportação final para um terceiro país (ZILLI et al, 2013).

Com relação ao tratamento tributário, não há a incidência de Imposto de Importação (II), Imposto sobre Produto Industrializado (IPI), Imposto sobre Circulação de Mercadorias e Serviços (ICMS) e Programa de Integração Social (PIS) e Contribuição para Financiamento da Seguridade Social (COFINS) importação, pois a Receita Federal considera que as operações Back to Back não caracterizam importação nem exportação (CIESP, 2013).

\section{PROCEDIMENTOS METODOLÓGICOS}

O presente trabalho caracterizou-se como uma pesquisa exploratória e descritiva quanto aos fins de investigação. A pesquisa exploratória consiste em conhecer profundamente o tema afim de criar familiaridade com o mesmo. Pode-se utilizar o levantamento 
bibliográfico ou entrevistas que estimulem o entendimento conteúdo. Diferente da pesquisa exploratória, a descritiva consiste na descrição do assunto através de questionário ou observação. Quanto à abordagem do tema, a pesquisa é de caráter qualitativo, ou seja, não requer o uso de métodos e técnicas estatísticas (SOUZA; FIALHO; OTANI, 2007).

Para Souza, Fialho e Otani (2007), a coleta de dados pode ser feita de duas formas: pesquisa documental (fonte primária) ou pesquisa bibliográfica (fonte secundária). Diante disso, a presente pesquisa emprega duas técnicas de coleta de dados: documentação direta e indireta.

A primeira parte da pesquisa utiliza-se da técnica de documentação indireta de fonte secundária. Essa técnica consiste no levantamento bibliográfico de informações por meio de trabalhos escritos com o objetivo de analisar e interpretar as fontes primárias e com outras obras consideradas fontes secundárias (SOUZA; FIALHO; OTANI, 2007).

A segunda parte da pesquisa envolve a documentação direta que é caracterizada por meio da coleta de dados no local onde ocorre o evento, ou seja, na empresa. Devido às informações serem coletadas no local onde ocorre o fenômeno, a pesquisa caracteriza-se também como uma pesquisa de campo (SOUZA; FIALHO; OTANI, 2007).

O procedimento técnico da pesquisa classifica-se como um estudo de caso, pois consiste num estudo aprofundado e exaustivo do tema específico. De acordo com Souza, Fialho e Otani (2007), o estudo de caso precisa ser relevante pelo potencial de abrangência que permite um amplo e detalhado conhecimento do caso, através da análise e interpretação.

\section{DISCUSSÃO E RESULTADOS}

O presente trabalho foi realizado com três pessoas que trabalham em uma das maiores empresas cerâmicas do Brasil. Cada entrevistado exerce um posto de liderança dentro de suas áreas de atuação. Essas pessoas foram escolhidas por causa do conhecimento que cada uma possuí acerca do tema proposto neste estudo. Os entrevistados serão conhecidos como Entrevistado 1, Entrevistado 2 e Entrevistado 3.

\subsection{A opção pelo Back-To-Back: uma visão dos envolvidos}

O Back to Back é definido pelo Banco do Brasil (2015) como uma operação que possibilita à uma empresa comprar um produto no exterior e vendê-lo a um terceiro, sem trânsito pelas fronteiras brasileiras. Ou seja, é uma operação que envolve três empresas, onde uma empresa intermediária compra um produto de um fornecedor no exterior e vende este 
produto para um cliente também no exterior, sem que a mercadoria entre no território da empresa intermediária.

Diante da definição de como funciona essa operação, o Entrevistado 1 afirmou que a motivação para começar a utilizar as operações Back to Back na empresa foi a identificação de oportunidades de negócios nos mercados externos, principalmente na América do Sul, onde a produção própria da empresa não conseguia suprir a demanda desse mercado. Portanto, foi identificado que havia uma necessidade no mercado externo que poderia ser preenchida com o uso das operações Back to Back, proporcionando a possibilidade de expansão do negócio, através do atendimento de mais necessidades e nichos de mercado que com a produção própria não seria possível atender. Desse modo, o entrevistado afirmou que essa operação trouxe como aspecto positivo o aumento do Market Share nos países abordados pela operação hoje.

O Entrevistado 3 também afirmou que a motivação para começar o Back to Back foi a identificação de oportunidades no mercado externo pela limitação da produção própria e como uma possibilidade de aumentar a receita da empresa. Porém, para esse entrevistado, os aspectos positivos que essa operação trouxe para a empresa foi o pensamento "fora-da-caixa", pois traz novas ideias para a empresa e mostra para mesma que é possível diversificar as operações, não se apoiando somente na produção própria. Outro aspecto positivo é a melhora do serviço oferecido pela empresa, pois é necessário que haja um controle mais rígido da qualidade e entrega dos produtos, devido ao mercado externo possuir uma exigência muito maior do que o mercado interno e, também, porque os riscos no mercado internacional são muito maiores. Essa operação também mostra que não há a necessidade de uma empresa ser focada exclusivamente em um determinado tipo de negócio, como a produção, mas que pode diversificar suas operações, tornando uma empresa produtora e comercializadora, independente de ser produto da empresa ou não.

Em resumo, o Back to Back pode fazer com que uma empresa se torne melhor, porque para atender o mercado externo é necessário oferecer produtos e serviços de qualidade. Também possui algumas vantagens como o ganho financeiro, a não incidência de impostos de importação, que deixa o produto com preços mais competitivos e a não circulação da mercadoria pelo território aduaneiro (BANCO CENTRAL DO BRASIL, 2015). Assim, faz com que a empresa procure sempre melhorar suas atividades para melhor atender esse mercado. 


\subsection{Os benefícios da utilização: porque continuar a utilizar?}

De acordo com o Banco do Brasil (2015), as vantagens que essa operação proporciona para as empresas são o ganho financeiro, pelo preço de venda ser maior que o de compra; a não incidência de impostos de importação, o que faz com que os produtos tenham um preço mais competitivo nos mercados alvos e a não há emissão do Registro de Exportação (RE), pois, a mercadoria não circula pelo território.

O Entrevistado 3 enxerga benefícios além dos que foram citados anteriormente, como a utilização de poucos recursos da empresa. Neste tipo de operação, as instalações da fábrica não são utilizadas para produzir o produto, portanto são necessárias poucas pessoas (em torno de 3 ou 4) para realizar a emissão e troca da documentação. Assim, é possível oferecer produtos com preços mais competitivos, além da possibilidade de oferecer produtos que não são produzidos pela empresa por não possuir a tecnologia necessária para isso, proporcionando a ampliação dos negócios.

Outro benefício citado pelo entrevistado, é o posicionamento no mercado nacional e internacional, que cria uma rede associativa baseada na memória de valor que os consumidores têm da marca e que atuam como um fator decisivo de compra (MARSDEN, 2002; TAVARES, 1998). Ante isso, o Entrevistado 3 menciona que há uma melhora na qualidade do serviço prestado pela empresa, pois essas operações exigem um alto padrão de qualidade devido às exigências do mercado internacional. $\mathrm{O}$ Entrevistado 1 corrobora essa afirmação dizendo que para essas operações é importante encontrar fornecedores que possuam produtos e serviços de qualidade semelhante ou superior ao da organização.

Ainda sobre o posicionamento no mercado, como benefício, o Entrevistado 3 argumenta que há um aumento no portfólio de produtos da empresa, desde o mais básico até o mais sofisticado, a empresa passa a se posicionar como uma empresa completa que busca propiciar soluções completas para o cliente. Além do posicionamento, o entrevistado observa que a tributação mais leve diminui os custos do produto, refletindo no preço final para o cliente. Por fim, o último benefício citado pelo Entrevistado 3 foi a facilidade com que se pode sair da operação. Como não é utilizado a capacidade fabril da empresa, ela pode simplesmente parar com as operações sem trazer riscos para a empresa.

Diante de todos esses benefícios expostos, os Entrevistados 1 e 3 relataram quais as futuras expectativas com relação a operação. O Entrevistado 1 espera que a empresa se posicione como um player mundial no mercado em que atua, além de ser reconhecido como 
uma importante fonte de suprimento. $\mathrm{O}$ entrevistado 3 complementa as expectativas dizendo que a empresa esperar maximizar os lucros, aumentar o retorno financeiro, o Market Share nos mercados em que atua e conseguir acesso as tecnologias dos produtos que a organização não produz.

Os benefícios são um grande atrativo na utilização do Back to Back e podem trazer importantes ganhos para as empresas, tanto na parte financeira quanto na parte de serviço. Segundo o Banco Central (2015), esses benefícios são o ganho financeiro na operação, não incidência de imposto de importação (torna os preços mais competitivos) e a não emissão do Registro de Exportação (mercadoria não circula pelo território aduaneiro). Porém, é uma operação que exige um bom conhecimento acerca do comércio exterior, exigindo pessoas qualificadas para trabalhar com Back to Back.

\subsection{A importância da qualificação dos envolvidos}

Para Carvalho (2000), a mudança de uma sociedade industrial para uma sociedade do conhecimento trouxe novas formas de gestão nas organizações. Ao invés de focar em capital e trabalho padronizado para se obter sucesso organizacional, as empresas passaram a investir em pessoas e nas informações para criar e obter conhecimento para si. Desse modo, o conhecimento se tornou uma arma de extrema importância dentro e fora das organizações.

$\mathrm{Na}$ empresa onde foi realizado a pesquisa não é diferente. Segundo o Entrevistado 1, para se trabalhar com as operações Back to Back é necessário ter um conhecimento mais aprofundado do que o que é preciso para as operações de importação e exportação normais, pelo risco envolvido na operação. O Entrevistado 3 agrega essa resposta afirmando que o conhecimento técnico, operacional e tributário é muito importante para trabalhar com essas operações.

O Back to Back possui um alto risco, porque o acompanhamento é "virtual". Os produtos não vêm para o Brasil para que seja feita uma rechecagem dos mesmos. Por esse motivo é importante ter um fornecedor sério e comprometido para não haver problemas quando o produto chegar para o cliente. O Entrevistado 3 atesta a afirmação do Entrevistado 1 dizendo que para trabalhar com essa operação é necessário ter o know-how sobre os fornecedores, além de um bom relacionamento com os mesmos em termos de entrega, pois são operações longas. 
O Entrevistado 1 ainda lista que áreas são necessárias para se trabalhar nessa operação: área comercial, área de fornecimento, área operacional e área logística. A área comercial é responsável por fazer as ofertas para os clientes. A área de fornecimento capta as oportunidades e atende as demandas comerciais. $\mathrm{O}$ operacional faz a ponte entre a demanda da área comercial e os fornecedores. E a área logística cuida da parte documental e transporte da carga. Sendo a equipe da área operacional responsável por coordenar as áreas comercial, de fornecimento e logística.

O conhecimento técnico e operacional do funcionamento do comércio exterior é imprescindível para trabalhar com as operações Back to Back. Também é necessário conhecer os trâmites tributários dessa operação para os envolvidos saberem que não há a incidência de Imposto de Importação (II), Imposto sobre Produto Industrializado (IPI), Imposto sobre Circulação de Mercadorias e Serviços (ICMS) e Programa de Integração Social (PIS) e Contribuição para Financiamento da Seguridade Social (COFINS) importação, pois a Receita Federal considera que as operações Back to Back não caracterizam importação nem exportação (CIESP, 2013).

Além disso é muito importante que haja um bom relacionamento entre as áreas envolvidas no processo. Isso tudo é importante para que cada envolvido na operação se sinta confortável para trabalhar com o Back to Back.

\subsection{A importância da marca para o processo}

Como já mencionado anteriormente, a marca começou a ser usada na Idade Média com o intuito de identificar, diferenciar e proteger o produto dos fabricantes, bem como para facilitar a distinção dos produtos pelos consumidores. (KOTLER, 1995). Entretanto com a evolução do mercado e o crescimento do número de empresas, o conceito de marca evoluiu junto. A marca já não era utilizada somente para identificação e proteção dos produtos, ela passou a utilizar estratégias para agregar valor aos produtos e serviços.

Isto posto, os envolvidos argumentaram sobre a importância da marca nos processos de Back to Back. O Entrevistado 1 afirma que para fazer o Back to Back não é necessário ter marca, no entanto a marca ajuda. Por exemplo, é possível fazer o Back to Back sem que o cliente saiba, porém depende do tipo de cliente que se quer abordar. Se um cliente estiver buscando preços baixos, a marca não terá relevância. Mas, para o nível da empresa pesquisada, a marca é fundamental para realizar essas operações. 
Essa visão é partilhada pelos Entrevistados 2 e 3. O Entrevistado 3 ratifica a fala do Entrevistado 1, dizendo que a marca não é um fator determinante para ocorra a operação, mas é importante, porque a marca é usada como argumento de venda devido a muitas empresas comprarem diretamente com as empresas utilizadas pela empresa para fazer o Back to Back. Então, por que fazer o Back to Back? Por causa do know-how da operação, do forte relacionamento com os principais fornecedores e o prazo de pagamento maior que se comprasse diretamente com os fornecedores. Diante disso, os clientes preferem deixar os trâmites comerciais e logísticos à cargo da empresa, mesmo sabendo que pagarão um pouco mais caro, porém eles terão a garantia de um serviço de qualidade

Na visão da Entrevistada 2, isso tudo mostra que uma marca forte transmite confiança e dá segurança na realização da operação Back to Back, pois não se vende somente o produto, se vende várias coisas agregadas a esse produto, como qualidade, segurança e serviço, o que também demonstra a influência da marca na operação.

Os três entrevistados explicam a influência que uma marca pode ter dando o exemplo da Nike. Segundos eles, o funcionamento da Nike é, praticamente, como um Back to Back, pois os produtos da marca são desenhados em um país, produzidos em outros países e vendidos em quase todo o mundo. As pessoas estão comprando o produto por causa da marca, e não por quem o produz. O entrevistado 3 ainda cita o iPhone da Apple e a camisa da Lacoste como exemplos da força da marca e afirma que se não fosse a marca, os produtos dessas três empresas citadas não teriam tanta força.

Ante isso, o Entrevistado 1 entende que a marca, através de seus atributos e serviços, precisa fazer com que o cliente queira pagar mais para adquirir os produtos, pois nas operações Back to Back não é possível vender mais barato para o cliente do que ele conseguiria comprar direto com o fornecedor. Portanto, a marca sustenta a adição de valor, porque com uma marca forte os consumidores absorvem os atributos, oferecidos e garantidos na operação, mais facilmente.

Portanto, as marcas são capazes de criar vantagens competitivas únicas e muito difíceis de imitar, devido aos atributos que uma marca possui e que fazem com que o consumidor escolha um produto ou serviço de uma determinada marca ao invés da concorrente (TAVARES, 1998). 
Atributos de marca são características de identificação que diferenciam uma marca de sua concorrente. Ou seja, é o que faz o consumidor preferir determinada marca em relação a sua concorrente (TAVARES, 1998).

Diante disso, o Entrevistado 3 afirma que é importante ter um produto de qualidade, porque como é uma operação nova, é importante ganhar a confiança do cliente. Como os produtos não passam pela inspeção de qualidade da empresa intermediária, a operação pode ser colocada a perder. Segundo o Entrevistado 1, o cliente tem a expectativa de receber um produto de alta qualidade, portanto a escolha do fornecedor é de extrema importância nesse tipo de operação, já que os custos para resolver problemas no exterior são muito mais elevados que para resolver no mercado nacional.

O Entrevistado 2 possui uma visão semelhante à do Entrevistado 3. O segundo entrevistado considera extremamente importante ter um produto de qualidade, pois o processo de troca no exterior é muito mais complicado, por isso é preciso que o produto tenha garantia de qualidade para que não haja esse tipo de problema.

O Entrevistado 1 também compartilha da visão dos Entrevistados 2 e 3. Ele diz que é fundamental ter produtos de qualidade, porque quem compra da empresa tem uma expectativa de adquirir produtos de alta qualidade e a organização não pode arriscar ter problemas com a qualidade do produto que possa comprometer a imagem da marca, pois por trás da marca existe toda uma expectativa criada pelo mercado em receber produtos e serviços de qualidade. Mas, o Entrevistado 1 afirma que é possível fazer a operação de Back to Back com produtos de qualidade baixa, tudo depende do mercado abordado e do posicionamento estratégico da empresa.

O primeiro entrevistado afirma ainda que é importante ter uma ampla variedade de produtos, porque isso possibilita atingir mais mercados. Porém, para o ramo em que a indústria atua é complexo de se fazer isso, porque a produção não é flexível ao ponto de conseguir produzir diversos tipos diferentes de produtos. O Entrevistado 3 complementa o ponto de vista do Entrevistado 1 dizendo que um portfólio amplo dá mais opções para o cliente e passa segurança para ele, pois mostra que a empresa não está testando o Back to Back, mas que tem um processo estruturado e que funciona. Entretanto, o terceiro entrevistado alerta que não pode ter qualquer produto no portfólio, é preciso selecionar cuidadosamente para que a operação não comprometa a marca se o fornecedor escolhido não for confiável, ou, como afirma o Entrevistado 2, sejam produtos que a empresa não consiga 
produzir ou que não conflitem com os produtos produzidos internamente, porque, desse modo, a empresa acabaria concorrendo com a própria empresa.

Desse modo, estes atributos criam uma diferenciação para a operação, pois, de acordo com o Entrevistado 1 mesmo sendo um produto que não é produzido pela empresa, ele tem o mesmo nível de qualidade de um produto que é produzido internamente e que o cliente já está acostumado. Os entrevistados 2 e 3 compartilham do mesmo ponto de vista. Eles acreditam que a diferenciação que esses atributos trazem para a operação é confiança, credibilidade e segurança, pois o cliente sabe que irá receber um produto de qualidade e não se importará em pagar um pouco mais caro.

Portanto, os atributos de marca devem proporcionar benefícios para os consumidores que os façam querer comprar o produto da empresa ao invés da concorrente não importando qual o preço do produto (TAVARES, 1998).

Diante disso o Entrevistado 2 afirma que não existe uma empresa sem que essa tenha uma marca, porque é através da marca que a empresa consegue transmitir para o cliente sua identidade e é a marca que dá um norte para a empresa seguir. Por exemplo, para o Entrevistado 1, se a Europa aplicar medidas protecionistas contra a entrada de produtos da China, os importadores europeus terão que buscar novos fornecedores para suprir suas necessidades. Se a marca é reconhecida no mercado mundial, ela ajudará a empresa a penetrar nesse mercado. Aí a marca expandirá seu conhecimento nesse mercado através de seus produtos.

Do ponto de vista do Entrevistado 3, a medida que a marca vai ganhando reconhecimento através do atendimento das necessidades do cliente, o desejo de compra também aumenta. Desse modo, quanto mais conhecida uma marca é, maior é o desejo das pessoas de adquirirem o produto, o que agrega valor para a empresa. Portanto, a marca se torna importante para a empresa, pois fortalece a identidade entre cliente e empresa, ou seja, os clientes se identificam com a marca, o que faz com que eles queiram comprar os produtos ou serviços da marca.

Para que ocorra a identificação do cliente com uma marca, as empresas utilizam a comunicação para compartilhar conjunto de associações que o estrategista de marca procura criar ou manter. Esse conjunto de associações resulta na identidade da marca ou da concepção que a marca tem de si e espera que seja percebida pelos clientes (DIAS, 2014; AAKER; JOACHIMSTALER, 2000). 
O Entrevistado 2 cita que o valor da marca Coca-Cola é muito maior que o valor de todas as fábricas juntas, por causa do reconhecimento da marca. O Entrevistado 3 afirma que existe uma relação entre marca e consumidor, que o consumidor se identifica com a marca. De acordo com o segundo entrevistado, a Coca-Cola pode colocar sua marca numa camiseta que todo mundo enxergará, não precisa estar numa garrafa de refrigerante. Isso se dá porque a marca Coca-Cola não é reconhecida somente como uma marca de refrigerante, mas também é reconhecida por seus valores. Os valores da Coca-Cola são reconhecidos facilmente e influenciam as pessoas a adquirirem seus produtos.

O Entrevistado 3 corrobora a assertiva acima dizendo que as pessoas compram uma marca, porque se identificam com ela seja o motivo que for. A identificação pode ocorrer pelos atributos, pelo design, pelo nome ou pelo que ela oferece para os consumidores. Por exemplo, um celular da Apple em relação a um celular da Motorola pode ser tecnicamente igual, porém algumas pessoas podem preferir o da Apple porque o design agrada mais ou a marca cria o desejo por aquele produto. Diante do exposto, o Entrevistado 2 questiona, quem não é influenciado pela marca? Quem não escolhe comprar um produto da Apple, que é semelhante a um Samsung, somente por ser um Apple.

A segunda entrevistada ainda afirma que quando a marca consegue transformar um produto ou serviço em um desejo, ela faz com que os consumidores comprem o produto ou serviço de uma empresa ao invés de comprar do concorrente.

Segundo o Entrevistado 3, isso se dá, pois, os valores da empresa são um reflexo do que a marca representa, pois, eles são aplicados na construção da marca. Todos os valores da empresa são transferidos para a marca, fazendo ela crescer e quem faz a marca crescer são as pessoas que trabalham na empresa. O conhecimento das pessoas é considerado um recurso muito importante para o desenvolvimento das empresas, pois, assim, elas criam vantagem competitiva (TERRA, 2001; RÉGIS, 2009). Desse modo, a vantagem competitiva auxilia na construção da marca, pois nos dias atuais a concorrência acirrada e as constantes exigências dos clientes tornam a marca um diferencial no mercado (MAGALHÃES, 2006).

Como a competição no mercado está acirrada, o Entrevistado 2 afirma que a marca auxilia a empresa na concorrência contra as demais organizações. Neste contexto, o serviço é o diferencial de uma marca, pois dá mais confiança para o cliente na hora de comprar. $\mathrm{O}$ Entrevistado 3 complementa a visão do segundo entrevistado dizendo que a marca é decisiva no auxílio da concorrência do mercado, pois uma marca reconhecida no mercado e desejada 
pelos consumidores facilita muito os negócios da empresa e proporciona um poder muito grande frente aos concorrentes. Por exemplo, se uma loja de construção é aberta, ela tem que ter uma marca muito desejada no mercado, pois essa marca se torna uma marca âncora, a qual atrai muitos clientes para a loja.

Segundo o Entrevistado 2, isso ocorre devido aos clientes notarem que os valores da empresa estão consoantes com o que os clientes percebem da imagem da marca da empresa. Sendo que a imagem da marca, é a decodificação feita pelo público de todos os sinais emitidos pela marca (KHAUAJA, 2008). Por exemplo, a empresa possui a transparência como um valor, portanto se houver uma reclamação do cliente a respeito do produto, os colaboradores da empresa não esconderam do cliente o problema, pelo contrário eles admitirão o erro e buscaram uma solução para resolver o problema. Quando os valores da marca estão claros na cabeça das pessoas que trabalham na empresa, sempre que existirem problemas os valores da empresa darão um norte para seguir.

Os valores são transmitidos para a marca e os clientes notam quando os colaboradores estão colocando os valores em prática, gerando valor para a marca. Hoje em dia os consumidores enxergam muito mais o lado humano das empresas, quando ela mostra para os clientes que se importa com as pessoas que trabalham ao seu redor e quando ela mostra que está preocupada com o impacto que a mesma causa no ambiente, isso agrega valor para a marca.

Como o Entrevistado 3 afirmou, as pessoas compram uma marca porque elas se identificam com os valores que são traduzidos para ela e criam vínculos emocionais. Esse processo é conhecido como Branding, que é definido como a criação de laços emocionais entre a marca e o consumidor, baseados na informação captada por nossos sentidos (LINDSTROM, 2007).

$\mathrm{O}$ vínculo emocional entre a marca e o consumidor, visa ganhar a lealdade do cliente. A lealdade à marca é a razão pela qual o consumidor continua comprando de uma determinada marca mesmo havendo concorrentes com características superiores ou preços menores (AAKER, 1998).

\section{CONSIDERAÇÕES FINAIS}

As organizações do conhecimento se utilizam dos ativos tangíveis e intangíveis para gerarem um resultado econômico futuro, ou seja, esses ativos representam a riqueza de uma 
empresa. A marca é um dos principais ativos intangíveis das organizações baseadas no conhecimento e a principal fonte geradora de valor.

Com isso, a construção da marca passou a ser um importante fator de vantagem competitiva para as empresas. Através da identidade e imagem da marca, as organizações buscam criar associações através de vínculos emocionais entre a marca e o consumidor a fim de posicionar sua marca tanto no mercado nacional, como no internacional.

O Back to Back surge como uma opção para suprir uma necessidade identificada no mercado internacional, onde a empresa não consegue suprir a demanda desse mercado com a produção própria.

A operação Back to Back proporciona diversas vantagens para a empresa que a utiliza, como preços mais competitivos devido a não incidência dos impostos de importação e exportação, exceto o PIS/COFINS exportação, não utiliza as dependências da fábrica, utiliza poucos recursos da empresa, possibilidade de oferecer produtos que a empresa não tem capacidade de produzir, o aumento do portfólio de produtos da empresa e a fácil saída da operação.

Portanto, o Back to Back é um fortalecedor de marca pois com essa operação é possível oferecer para o cliente produtos que a empresa não consegue produzir internamente por não possuir a tecnologia necessária para tal. Então, o Back to Back atua como fortalecimento de marca quando oferece opções de produtos que a empresa não consegue produzir, não quer produzir ou não tem interesse em produzir.

\section{REFERÊNCIAS}

AAKER, D. A. O Papel das Marcas. In: AAKER, D. A. Marcas: Brand Equity gerenciando o valor da Marca. 13 ed. São Paulo: Elsevier, 1998, p. 7-8.

AAKER, D. A. Marcas: brand equity gerenciando o valor da marca. 13 ed. São Paulo: Elsevier, 1998.

BANCO CENTRAL DO BRASIL. Disponível em: $<$ http://www.bcb.gov.br/pre/bc_atende/port/expImp.asp\#15>. Acesso em: 18 out. 2015.

BANCO DO BRASIL. Disponível em: <http://wwwbb.com.br/portalbb/page44,3389,10433,0,0,1,2.bb?codigoMenu=13199\& codigoNoticia $=21553 \&$ codigoRet $=13219 \&$ bread=13> . Acesso em: 18 out. 2015

BRITO, R. A. B.; ZUZA, M. S. P. Branding. Revista CEPPG, n. 21, p. 92-113, 2009. 
CARVAlHO, F. C. A. Gestão do Conhecimento: o caso de uma empresa de alta tecnologia. 2000. 130 f. Tese (Pós-Graduação em Engenharia de Produção) - Universidade Federal de Santa Catarina, Florianópolis, 2000.

CIESP. Disponível em: 〈http://www.ciesp.com.br/pesquisas/analise-operacao-backto-back/>. Acesso em: 19 out. 2015.

DAVENPORT, T. H.; PRUSAK, L. Conhecimento empresarial: como as organizações gerenciam o seu capital intelectual. 8 ed. Rio de Janeiro: Campus, 1998.

DIAS, S. R. (Org.). Gestão de marketing. São Paulo: Saraiva, 2003.

FISCHMANN, A. A.; JOÃO, B. N.; MAGALHÃES, T. B. Estratégias baseadas no conhecimento (KBV): um estudo da companhia vale do rio doce - CVRD. In: II ENCONTRO DE ESTUDOS EM ESTRATÉGIA - 3E`s - ANPAD, 2005, RIO DE JANEIRO. 3E`s ANPAD, 2005. v. 1.

KHAUAJA, D. M. R. Gestão de marcas na estratégia de internacionalização de empresas: estudo com franqueadoras brasileiras. 2009. Tese (Doutorado em Administração) - Programa de Pós-Graduação em Administração, Faculdade de Economia, Administração e Contabilidade, Universidade de São Paulo, 2009.

KOTLER, P. Administração de marketing: análise, planejamento, implementação e controle. 3 ed. São Paulo: Atlas, 1995.

LINDSTROM, M. Brand sense: a marca multissensorial. Porto Alegre: Artmed, 2005.

LLAMAS, E. La naturaleza estratégica del proceso de branding. Centro de Estudios en Diseño y Comunicación, p. 223-228, 2013.

MAGALHÃES, T. A. Valor da marca para o consumidor: um estudo empírico no setor automotivo. 2006. Tese (Mestrado em Administração) - Universidade FUMEC, Belo Horizonte, 2006.

MARSDEN, P. Brand positioning: meme's the word. Marketing Intelligence \& Planning, v. 20, n. 5, p. 307-312, 2002.

MELO, E. L. M. Condicionantes para integração estratégica da TI em organizações baseadas em conhecimento: estudos de caso. 2010. 112 f. Dissertação (Mestrado em Gestão do Conhecimento e da Tecnologia da Informação) - Universidade Católica de Brasília, Brasília, 2010.

SOUZA, A. C.; FIALHO, F. A. P.; OTANI, N. TCC: métodos e técnicas. Florianópolis: Visual Books, 2007.

RÉGIS, J. F. V. A gestão do conhecimento e a inovação tecnológica como fatores de sobrevivência e de competitividade na sociedade do conhecimento: uma análise exploratória das MPEs do Rio Grande do Norte. 2009. 175 f. Tese (Pós Graduação em Engenharia de Produção). Universidade Federal do Rio Grande do Norte, Natal, 2009.

SANTOS, N. Gestão do Conhecimento Organizacional. Apostila criada para o Programa de Pós-Graduação em Engenharia e Gestão do Conhecimento. Florianópolis, 2005.

TAVARES, M. C. A força da marca: como construir e manter marcas fortes. São Paulo: Harbra, 1998. 
TIGRE, P. B. Economia da informação e do conhecimento. Boletim de conjuntura economia \& tecnologia, ano 1, v. 2, 2005.

TERRA, J. C. Gestão do Conhecimento: o grande desafio empresarial. São Paulo: Negócio Editora, 2001.

ZILLI, J. C.; GALLARDO, M. L. R.; DAL TOÉ, R. A.; DANDOLLINI, G.A.; SOUZA, J. A. Os procedimentos na utilização de operações back to back em uma empresa de revestimentos cerâmicos do sul de Santa Catarina. In: Congresso Virtual Brasileiro de Administração. 2003. 